\title{
Effect of $n$-hexane and aqueous extracts of cashew nuts on some pathogenic organisms obtained from general out patients, Ibadan, Nigeria
}

\author{
Salami O. O. ${ }^{1 *}$, Atoyebi T. J. ${ }^{1}$, Afolabi Q. $0 .{ }^{2}$, Obisesan L. $0 .{ }^{1}$ and Obero J. $0{ }^{2}$ \\ ${ }^{1}$ Microbiology Unit, Science Laboratory Technology Department, Federal College of Animal Health and Production \\ Technology, P.M.B. 5029, Moor Plantation, Apata, Ibadan, Oyo State, Nigeria. \\ ${ }^{2}$ Chemistry Unit, Science Laboratory Technology Department, Federal College of Animal Health and Production \\ Technology, P.M.B. 5029, Moor Plantation, Apata, Ibadan, Oyo State, Nigeria.
}

Accepted 29 November, 2017

\begin{abstract}
The antimicrobial activity of $n$-hexane and aqueous extracts of the nut of cashew fruit Anacardium occidentale $\mathrm{L}$. was investigated on some pathogenic organisms of medical importance using agar well diffusion method. The test organisms are Proteus sp., Escherichia coli, Klebsiella pneumonia, Pseudomonas aeruginosa, Enterococcus cloacae and Acinetobacter baumanii. All the test organisms were identified to be sensitive to the extract at various concentrations $(0.10,0.20,0.30,0.40$ and $0.50 \mathrm{~g} / \mathrm{ml})$ except Acinetobacter baumanii. The greater the concentration of the extract, the higher the antibacterial activities exerted on the isolates. $K$. pneumonia was the most susceptible organism to the $\mathrm{n}$-hexane extract followed by $P$. aeruginosa. The least susceptible to the extract was Proteus sp. while $A$. baumanii was resistant to the extract. The most susceptible organism to the water extract was Pseudomonas aeruginosa while the least was E. cloacae. Therefore, it is suggested that the extract could be used as antibiotic which may contribute to the improvement of health care delivery if the active chemical compounds capable of inhibiting the growth of the test bacteria are analysed and compounded into dosage forms for use.
\end{abstract}

Keywords: Cashew nut, n-hexane, pathogenic, agar well diffusion, antibacterial.

${ }^{*}$ Corresponding author. E-mail: salamiolufunmi@yahoo.com. Tel: +2348028339370.

\section{INTRODUCTION}

Multiple drug resistance in human and animal pathogenic microorganisms have been commonly reported in recent years from all over the world, particularly in developing countries, due to indiscriminate use of commercial antibiotics in the treatment of infectious diseases (Service, 1995). Though, resistance development by microbes cannot be stopped, appropriate action will reduce the mortality and health care costs by using antibiotic resistant inhibitors of plant origin (Ahmad and Beg, 2001). Moreover, the traditional method of utilizing plants as remedies for diseases still occupy a central place among rural communities of developing countries in the absence of an efficient primary health care system (Ali et al., 2001). Medicinal plants represent a rich source of antimicrobial agents. Plants are used medicinally in different countries and are a source of many potent and powerful drugs (Srivastava et al., 2000). Ancardium occidentale $\mathrm{L}$. belonging to the family Anacardiaceae which has great economic and medicinal value. The cashew tree $(A$. occidentale) is a tropical evergreen tree that produces the cashew seed and the cashew apple. It

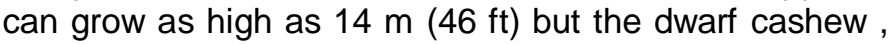
growing up to $6 \mathrm{~m}(20 \mathrm{ft})$, has proved more profitable with earlier maturity and higher yields (FAO, 2013; Akinpelu, 2001). The cashew seed, often simply called a cashew is widely consumed. It is eaten on its own, used in recipes or processed into cashew cheese or cashew butter. This is simply called cashew apple (FAO, 2013; Adebayo et al., 2003).

Cashew oil is dark yellow oil obtained by pressing cashew nuts and is used for cooking or salad dressing (typically broken chunks created during processing). This 
may be produced from a single cold pressing (Smart Kitchen, 2015). Cashew nutshell liquid (CNSL) or cashew shell oil is a natural resin with a yellowish sheen found in the honeycomb structure of the cashew nutshell, and is a byproduct of processing cashew nuts. It is a raw material of multiple uses in developing drugs, antioxidants, fungicides, etc. It is used in tropical folk medicine and for anti-termite treatment of timber (Tullo, 2008). Its composition varies depending on how it is processed. These substances are skin allergens, like the oils of poison ivy, and poses danger during manual cashew processing (Tullo, 2008; Hammed et al., 2008). Cashew shell oil may be used as a resin for carbon composite products (Ferri, 2011). The leaf of cashew is used in the treatment of wounds; based on the presence of tannin (Agedah et al., 2010). The extract of cashew bark helps to reduce congestion (Mahadevappa et al., 2011). The apple of cashew is used in the treatment of scurvy (disease caused by deficiency of vitamin C) (Lee et al., 2001). The use of the cashew nut shell oil on the sore of leprosy improves the healing activity (Prescott et al., 2006). Meanwhile binging on cashew nuts can lead to unnecessary weight gain because it is high in calories and too many cashews can cause stomach ache (Lee et al., 2001). However, the aim of this study is to investigate the effect of $n$-hexane and aqueous extract of cashew nuts on some pathogenic organisms. To investigate the antibacterial activities of the n-hexane extract of cashew nut on some pathogenic organisms and to compare the effect of the n-hexane extract of cashew nut to known commonly used antibiotics on the selected pathogenic organisms.

\section{MATERIALS AND METHOD}

\section{Sample collection}

Cashew nuts were purchased from Cocoa Research Institute of Nigeria (CRIN) in Ibadan, Oyo State. They were transported in a sterile container (polythene bag) to the Chemistry Laboratory of Federal College of Animal Health and Production Technology, Ibadan, Oyo state, Nigeria.

\section{Microbial strains and growth}

Pure strains of the sample microbes were obtained from the Medical Laboratory of the University College Hospital (UCH) Ibadan. This was further identified by sub culturing on appropriate agar. A wire loop was used to pick a colony of the isolate which was streaked on the pure media and allowed to grow for $24 \mathrm{~h}$ and incubated at $37^{\circ} \mathrm{C}$.

\section{Extraction}

The cashew nuts were washed with soap and water to avoid contamination and oven dried at a temperature of $72^{\circ} \mathrm{C}$ for $12 \mathrm{~h}$ through 7 days. The sample was shelled and re-dried again at a temperature of $42^{\circ} \mathrm{C}$ or $24 \mathrm{~h}$ after which it was pulverized using mortar and pestle into fine particles. The fine particles was then wrapped with aluminum foil and left for extraction. $200 \mathrm{~g}$ of the powdered sample was weighed and dispensed into a sterile conical flask, $300 \mathrm{ml}$ of the solvent ( $\mathrm{n}$-hexane) was added to the powder and stirred, it was left for $24 \mathrm{~h}$, the extract was filtered using Whatman filter paper, more solvent was added to the solution and filtration was carried out again until there was no more oil in the mixture. The extract was taken to the Central Laboratory at University of Ibadan to determine the concentration and separate the oil from the mixture using a rotary evaporator machine. The oil obtained was kept in the fridge for preservation until when needed.

\section{Preparation of media}

The media used are Mueller Hinton Agar (MHA) and MacConkey Agar. They were prepared according to manufacturer's instruction. $25 \mathrm{~g}$ of the agar was weighed and dispensed into a sterile conical flask; $150 \mathrm{ml}$ of distilled water was also measured and added to the agar. The mixture was stirred very well until it was homogeneous and heated in a microwave for $10 \mathrm{~min}$; it was sterilized at $121^{\circ} \mathrm{C}$ for $15 \mathrm{~min}$ and allowed to cool before pouring. It was incubated at $35^{\circ} \mathrm{C}$ for $24 \mathrm{~h}$ for bacterial count and observes the morphological features of bacterial colony. Sub culturing of different distinct colonies from bacteria growth was done on Mueller Hilton Agar (MHA) and stored at $4^{\circ} \mathrm{C}$ for biochemical test. All the bacterial isolates were identified on the basis of colony characteristics, morphological and biochemical reactions as described in Bergey's Manual of Determinative Bacteriology (Buchanan and Gibbons, 1974).

\section{Antibiotics susceptibility test}

Antibiotic susceptibility testing was performed for the antibiotics; Ceftazidime (CAZ)-30, Cefuroxime (CRX)-30, Gentamicin (GEN)10, Ciprofloxacin (CPR)-5, Ofloxacin (OFL)-5, Augumentin (AUG)30, Nitrofurantoin (NIT)-300, Ampicillin (AMP)-10, by Kirby bauer disc diffusion technique (Bauer, 2003) with quality control strain of Pseudomonas aeruginosa (950), Klebsiella pneumonia (8588) and Enterococcus cloacoae (36102) as per National Committee for Clinical Laboratory Standards (NCCLS). A wire loop was used to pick a colony of pure culture and Thereafter, was transferred into a tube containing $5 \mathrm{ml}$ of tryptic soya broth (TSB) and mixed gently until it formed a homogenous suspension. Bacterial suspension matching 0.5 McFarland turbidity standards were inoculated on Muller-Hinton Agar (See Appendix).

A sterile cotton swab was then dipped into the suspension and the excess was removed by gentle rotation of the swab against the surface of the tube and was used to distribute the bacteria suspension evenly over the entire surface of the Mueller Hilton Agar. The inoculated plates were left at room temperature to dry for 3 to $5 \mathrm{~min}$. The plates were incubated at $37^{\circ} \mathrm{C}$ for $24 \mathrm{~h}$ to grow zones of inhibition. The zones of inhibition were measured using a meter rule.

\section{Agar well diffusion method}

The antibacterial activity of $70 \% \mathrm{n}$-hexane of the various concentrations $(0.10,0.20,0.30,0.40$ and $0.50 \mathrm{~g} / \mathrm{ml})$ of the cashew nut extract against some pathogenic isolates from hospitalized patients were evaluated using agar well diffusion method according to the National Committee for Clinical Laboratory Standard (NCCLS). 3 to 5 morphologically identical colonies from each agar plate were lifted with a sterile wire loop and transferred into a tube containing $5 \mathrm{ml}$ of tryptic soya broth (TSB). The turbidity of each bacterial suspension was adjusted to reach an optical comparison to that of $0.5 \mathrm{McF}$ arland standards, resulting in suspension containing approximately 1 to $2 \times 10^{8} \mathrm{CFU} / \mathrm{ml}$. Mueller-Hinton Agar 
plates were inoculated by streaking the swab over the entire sterile agar surface.

This procedure was repeated by streaking two more times, rotating the plates approximately $60^{\circ}$ each time to ensure even distribution of the inoculum. As a final step, the rim of the agar plate was also swabbed. After allowing the inoculum to dry at room temperature, $6 \mathrm{~mm}$ diameter wells were bored with sterile metal borer. Each extract was checked for antibacterial activity by introducing the various concentrations $(0.1,0.2,0.3,0.4$, and 0.5 $\mathrm{g} / \mathrm{ml}$ ) into duplicate wells using sterile micropipette. The plates were allowed to stand at room temperature for one hour to allow diffusion of extract into the agar. Then, plates were incubated at $37^{\circ} \mathrm{C}$ for 18 $\mathrm{h}$ in upright position. The presence of zone of inhibition was regarded as the indicator of antimicrobial action and the antimicrobial activity of extract was expressed in terms of average diameter of zone inhibition measured in millimeters. Each test was carried out in triplicate (See Appendix).

\section{RESULTS AND DISCUSSION}

The zones of inhibition observed around the wells, indicated the antibacterial activities of the plant extract. The sensitivity of the different test organisms to n-hexane extracts of Anacardium occidentale (cashew nut) was shown by zones of inhibition after $24 \mathrm{~h}$ of incubation (Table 1). The absence of zones of inhibition around each well signified resistance in Acinetobacter baumannii. It was observed that water extract (aqueous) which was used as control did inhibit the growth of most of the test bacteria (Table 2). The $n$-hexane extracts of the nuts which showed potency in their bactericidal action, when compared to the antibiotics which were bacteriostatic against some of the test bacteria with the exception of $A$. baumannii (Table 3 ). It was also observed that as the concentrations increases the zone of inhibition also increases except for Proteus sp. which decreases as the concentration increases and $A$. baumannii which shows no growth with the concentration (Table 1)

There were significant differences in the antimicrobial effects of extracts obtained from nuts of $A$. occidentales using n-hexane solvent compared to the aqueous extracts (Table 1). The $\mathrm{N}$ - Hexane extract of the nuts of $A$. occidentale was more effective than the aqueous extracts. This might be due to the ability of the solvent to extract more of the active ingredients (bioactive compounds) from the plant materials. Table 2 shows the efficacy of the aqueous extract on the bacterial strains with Pseudomonas aeruginosa having higher zone of inhibition when compared with $\mathrm{n}$-hexane extract.

The traditional preparation of decoction from medicinal plants for the treatments of various diseases involves water (cold or hot) or other solvents extractions of parts of plants such as seeds, roots, stems, bark and leaves. The above observation suggests that the active ingredients from the nuts of $A$. occidentale are more soluble in n-hexane, a non-polar solvent (possibly due to the fact that it contains active chemicals that are nonpolar in nature) than in water. This concurs with the work of Duke (2001) and Kubo et al. (1993) who reported that several investigations on medicinal plants indicated that organic solvents such as ethanol, methanol and nhexane are extensively used for crude extraction, before being re-extracted to obtain purified active compounds.

The higher potency of $n$-hexane extracts might be connected with the extraction solvent. N-hexane has been shown to have a greater extractive power than water. This present work agrees with the work of Ferri (2011) who observed that the presence of $n$-hexane and ethanol in addition to achieving better extraction may also enhance the efficacy of the active ingredients. This research suggest that $n$-hexanolic extracts of screened plants would be helpful in treating diseases in man caused by enterotoxin producing bacteria namely; Proteus sp., Pseudomonas aeruginosa, Escherichia coli and Klebsiella pnuemoniae.

The antibacterial activities of the extracts increased as the concentration increased as found out in this work except for Proteus sp. and none for $A$. baumannii. This corroborates the research findings of Banso and Adeyemo (2007) who reported that the tannins isolated from medicinal plants possess remarkable toxic activity against bacteria and fungi and may assume pharmacological importance in future. The potentials of any drug depend on the active ingredient present in it. The results obtained from this research tend to confirm the efficacy of the extracts of the nuts of $A$. occidentale as traditional remedies against enterotoxin producing bacteria.

Table 1. Zone of inhibition $(\mathrm{mm})$ for the studied bacterial strains that characterize the antibacterial activity of $n-h e x a n e$ extract of cashew nut.

\begin{tabular}{lccccc}
\hline \multirow{2}{*}{ Organisms } & \multicolumn{5}{c}{ Concentration of extract $\mathbf{( g / m l )}$} \\
\cline { 2 - 6 } & $\mathbf{0 . 1 0}$ & $\mathbf{0 . 2 0}$ & $\mathbf{0 . 3 0}$ & $\mathbf{0 . 4 0}$ & $\mathbf{0 . 5 0}$ \\
\hline Proteus sp. & $35 \pm 02$ & $30 \pm 01$ & $31 \pm 01$ & $30 \pm 01$ & $25 \pm 01$ \\
Escherichia coli & $40 \pm 02$ & $45 \pm 02$ & $46 \pm 02$ & $46 \pm 02$ & $50 \pm 01$ \\
Klebsiella pneumonia & $43 \pm 12$ & $43 \pm 11$ & $45 \pm 01$ & $50 \pm 02$ & $60 \pm 10$ \\
Pseudomonas aeruginosa & $45 \pm 10$ & $45 \pm 01$ & $45 \pm 01$ & $46 \pm 02$ & $50 \pm 10$ \\
Enterococcus cloacae & $31 \pm 01$ & $32 \pm 01$ & $35 \pm 10$ & $42 \pm 01$ & $35 \pm 02$ \\
Acinetobacter baumannii & 0.00 & 0.00 & 0.00 & 0.00 & 0.00 \\
\hline
\end{tabular}

Keys: $\mathrm{g} / \mathrm{ml}$ - gram per milliliters, $\mathrm{mm}$ - millimeters. 
Table 2. Zone of inhibition $(\mathrm{mm})$ for the studied bacterial strains that characterize the antibacterial activity of aqueous extract of cashew nuts.

\begin{tabular}{lccccc}
\hline \multirow{2}{*}{ Organisms } & \multicolumn{5}{c}{ Concentration $\mathbf{( g / m l )}$} \\
\cline { 2 - 6 } & $\mathbf{0 . 1 0}$ & $\mathbf{0 . 2 0}$ & $\mathbf{0 . 3 0}$ & $\mathbf{0 . 4 0}$ & $\mathbf{0 . 5 0}$ \\
\hline Proteus sp. & $27 \pm 20$ & $27 \pm 01$ & $29 \pm 30$ & $30 \pm 11$ & $30 \pm 10$ \\
Escherichia coli & $28 \pm 01$ & $30 \pm 02$ & $34 \pm 01$ & $36 \pm 01$ & $39 \pm 20$ \\
Klebsiella pneumonia & $42 \pm 10$ & $42 \pm 10$ & $43 \pm 10$ & $44 \pm 20$ & $44 \pm 20$ \\
Pseudomonas aeruginosa & $54 \pm 03$ & $56 \pm 03$ & $58 \pm 12$ & $58 \pm 12$ & $60 \pm 10$ \\
Enterococcus cloacae & $26 \pm 01$ & $26 \pm 01$ & $30 \pm 01$ & $32 \pm 02$ & $33 \pm 01$ \\
Acinetobacter baumannii & 0.00 & 0.00 & $0.20 \pm 00$ & $0.20 \pm 00$ & $0.20 \pm 00$ \\
\hline
\end{tabular}

Keys: $\mathrm{g} / \mathrm{ml}$ - gram per milliliters, $\mathrm{mm}$ - millimeters.

Table 3. Susceptibility test of the pathogenic organisms to commonly used antibiotics.

\begin{tabular}{lcccccc}
\hline $\begin{array}{l}\text { Antibiotics name/code/ } \\
\text { concentration }(\boldsymbol{\mu g})\end{array}$ & E. coli & $\begin{array}{c}\text { E. cloacae } \\
(\mathbf{3 6 1 0 2 )}\end{array}$ & Proteus sp. & $\begin{array}{c}\text { K. pneumoniae } \\
\text { (8588) }\end{array}$ & A. baumanii & $\begin{array}{c}\text { P. aeuroginosa } \\
\text { (950) }\end{array}$ \\
\cline { 2 - 7 } & 12.00 & 10.00 & 08.00 & 10.00 & 03.00 & NS \\
Ceftazidime (CAZ)-30 & 15.00 & $\mathrm{NS}$ & 10.00 & 7.00 & $\mathrm{NS}$ & $\mathrm{NS}$ \\
Cefuroxime (CRX)-30 & 20.00 & $\mathrm{NS}$ & $\mathrm{NS}$ & 20.00 & $\mathrm{NS}$ & 20.00 \\
Gentamicin (GEN)-10 & 9.00 & 22.00 & 22.00 & $\mathrm{NS}$ & 13.00 & 7.00 \\
Ciprofloxacin (CPR)-5 & 23.00 & 15.00 & 14.00 & $\mathrm{NS}$ & 15.00 & 21.00 \\
Ofloxacin (OFL)-5 & 6.00 & 6.00 & 6.00 & 2.00 & $\mathrm{NS}$ & 5.00 \\
Augmentin (AUG)-30 & 21.00 & 10.00 & 12.00 & 20.00 & $\mathrm{NS}$ & 10.00 \\
Nitrofurantoin(NIT)-300 & 18.00 & 12.00 & 2.00 & 2.00 & 7.00 & 3.00 \\
Ampicillin (AMP)-10 & &
\end{tabular}

Keys: $\mu \mathrm{g}$ - microgram, NS - not significant. E. coli - Escherichia coli, K. pneumonia- Klebsiella pneumonia, P. aeruginosa- Pseudomonas aeruginosa, E. cloacoe - Enterococcus cloacoe, A. baumanni-Acinetobacter baumanni.

\section{CONCLUSION}

A. occidentale may be effective in the treatment of disease or intoxication caused by the organisms used in this research and may contribute to the improvement of health care delivery in Nigeria. If the active chemical compounds capable of inhibiting the growth of the test bacteria are analyzed and compounded into dosage forms for use. Further studies need to be carried out to bring out the potentials of this plant in managing diarrhea, intoxication and other related gastrointestinal diseases.

\section{REFERENCES}

Adebayo LO, Diyaolu SA, 2003. Mycology and spoilage of retail cashew nuts. Afr J Biotechnol, 2(10): 369-373.

Agedah CE, Bawo DDS, Nyananyo BL, 2010. Identification of antimicrobial properties of cashew, Anacardium occidentale L. (Family Anacardiaceae). J Appl Sci Environ Manag, 14(3): 25-27.

Ahmad I, Beg AZ, 2001. Antimicrobial and phytochemical studies on 45 Indian medicinal plants against multi-drug resistant human pathogens. J Ethnopharmacol, 74: 113-123.

Akinpelu DA, 2001. Antimicrobial activity of Anacadium occidentale bark. Fitoterapia, 72(2): 286-287.

Ali ANA, Julich WD, Kusnick C, Lindequist U, 2001. Screening of Yemeni medicinal plants for antibacterial and cytotoxic activities. J Ethnopharmacol, 74: 173-179.
Banso A, Adeyemo SO, 2007. Evaluation of antimicrobial properties of tannins isolated from Dichrostachys cinerea. Afr J Biotechnol, 6(15): $1785-1787$

Bauer K, 2003. The standard interpretative chart by Kirby Bauer. As sited by Biemer, J. J (1973); Antimicrobial susceptibility testing by the kirby-bauer disc diffusion method. Ann Clin Lab Sci, 3(2): 135-140.

Buchanan RE, Gibbons ME, 1974. Bergeys Manual of Determinative Bacteriology. $8^{\text {th }}$ ed. Williams and Wilkins, Baltimore. pp: 305-318.

Duke JA, 2001. The green pharmacy, anti-aging prescriptions, herbs, foods and natural formulas to keep you young. Emmaus, Pennsylvania Rodale Press.

Ferri E, 2011. Bioresins Derived from cashew Nutshell oil. Materials today. Available at https://www.materialstoday.com/compositeprocessing/features/bio-resins-derived-from-cashew-nutshell-oil/. Retrieved on $7^{\text {th }}$ September, 2011. Accessed June 2017.

Food Agricultural Organization (FAO), 2013. Major food and Agricultural commodities and producers countries by commodity. Available at http://www.livestrong.com. Retrieved on $6^{\text {th }}$, September, 2015

Hammed LA, Anikwe JC, Adedeji AR, 2008. Cashew nuts and production development in Nigeria. Am Euras J Sci Res, 3(1): 54-61.

Kubo IM, Ochi PC, Vieira C, Komatsu S, 1993. Antitumor agent from the cashew Anacardium occidentale apple juice. J Agric Food Chem, 41: 1012-1015.

Lee WC, Lee MJ, Kim JS, Park SY, 2001. Food borne illness outbreaks in Korea and Japan studied retrospectively. J Food Protect, 64(6): 899-902.

Mahadevappa H, Martin SS, Kesturu SG, 2011. Emerging roles of anarcardic acid its derivatives: A pharmacological overview. Basic Pharmacol Toxicol, 110: 122-132.

Prescott LM, Harley JP, Klein AD, 2006. Food Borne Disease. WCB McGraw Hill, pp 946-950. 
Service RF, 1995. Antibiotics that resist resistance. Science, 270: 724727.

Smart Kitchen, 2015. Cashew oil.
https://www.smartkitchen.com/resources/cashew February, 15, 2015. Accessed June 2017.

Srivastava J, Lambert J, Vietmeyer N, 2000. Medicinal plants: An expanding role in development. World Bank Technical Paper. No. 320. 6. Bhuniaa, H.P, Basakb, A., Chakia, T.K., Nandoa, G.B. Synthesis and characterization of polymers from cashew nut shell liquid: a renewable resource V. Synthesis of copolyester. Eur. Polym. J. 36, 1157-1165.

Tullo AH, 2008. Naturally occurring phenol compounds in cashew shells are becoming increasingly useful to industry. A Nutty Chem Chem Eng News, 86(36): 26-27.
Citation: Salami 00, Atoyebi TJ, Obisesan LO, Afolabi QO, Obero JO, 2017. Effect of $n$-hexane and aqueous extracts of cashew nuts on some pathogenic organisms obtained from general out patients, Ibadan, Nigeria. M icrobiol Res Int, 5(4): 55-61. 
APPENDIX

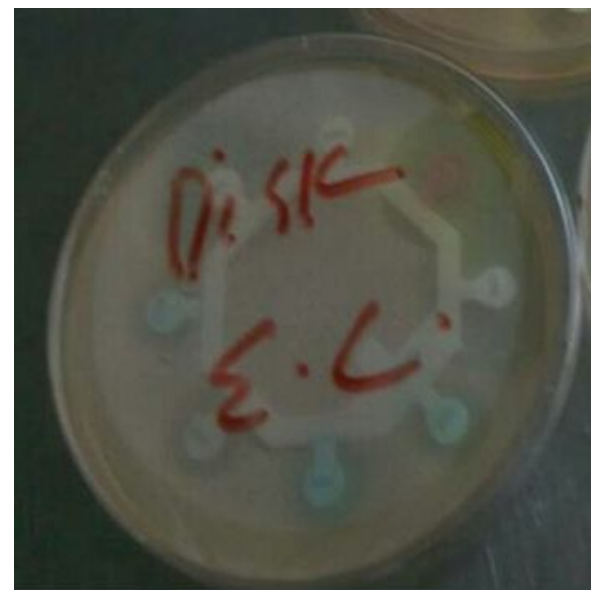

Sensitivity disc: Escherichia coli

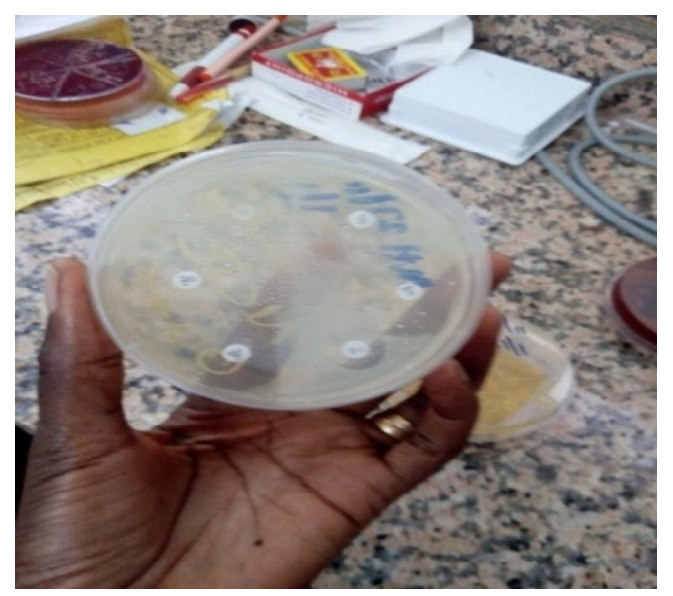

Proteus sp.

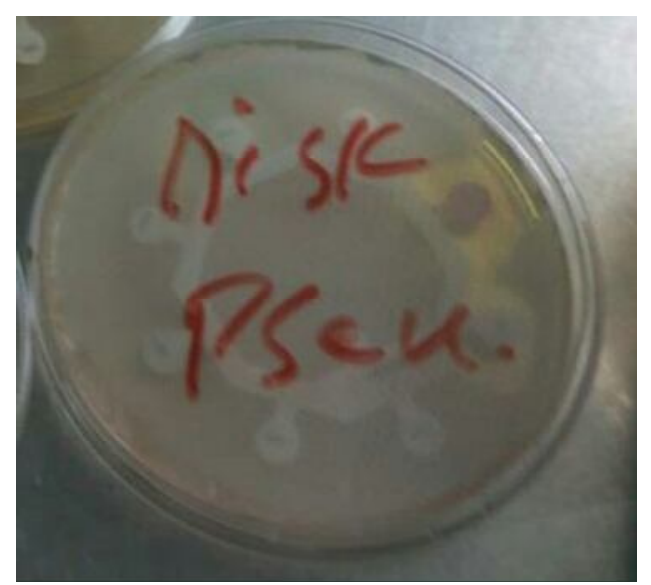

Sensitivity disc: Pseudomonas aeruginosa

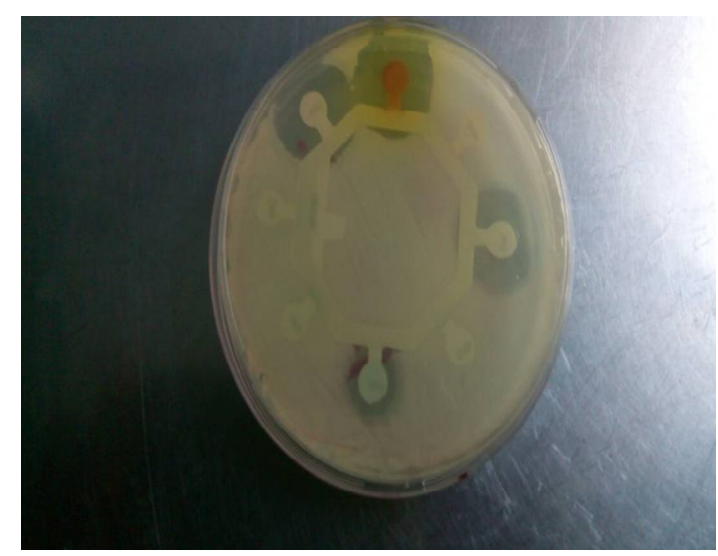

Sensitivity disc of E. coli 


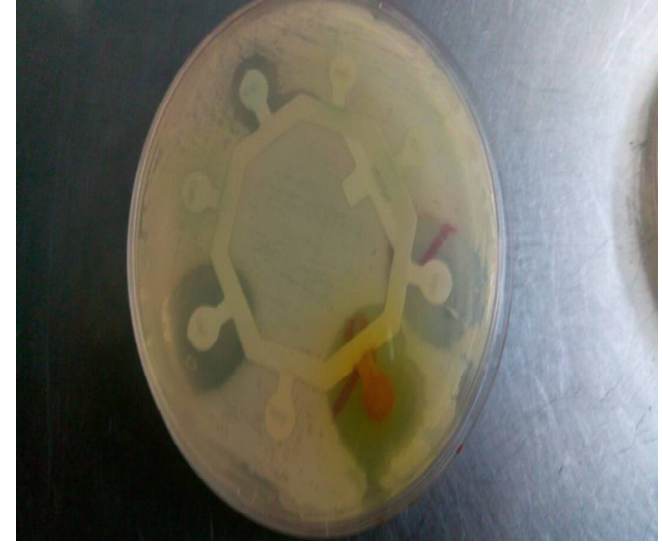

Sensitivity disc: Pseudomonas aeruginisa

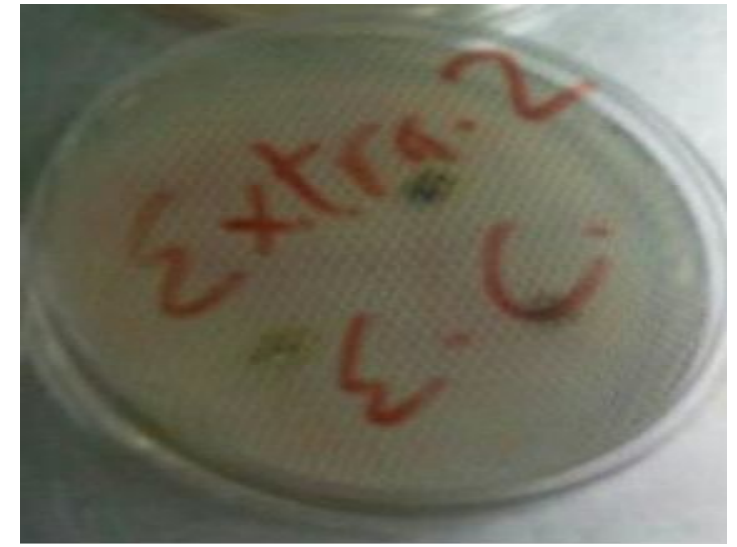

Extract: E. coli

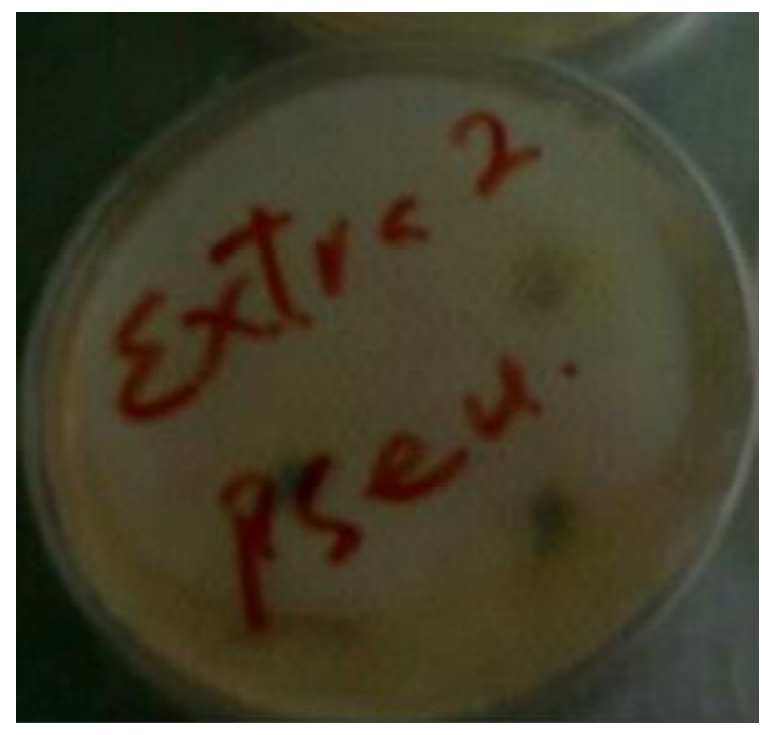

Extract: Pseudomonas aeruginosa 